\title{
From 2D digital imaging to finite element analysis using the ENEAGRID high performance computing infrastructure for the preservation of historical masonry structures
}

\author{
Marialuisa Mongelli* \\ Department of Energy Technologies, \\ ENEA C.R. Casaccia, \\ Via Anguillarese 301, 00123 Rome, Italy \\ Email: marialuisa.mongelli@enea.it \\ ${ }^{*}$ Corresponding author

\section{Irene Bellagamba, Francesco lannone and Giovanni Bracco}

Department of Energy Technologies,

ENEA C.R. Frascati,

Via Enrico Fermi 45, 00044 Frascati, Rome, Italy

Email: irene.bellagamba@enea.it

Email: francesco.iannone@enea.it

Email: giovanni.bracco@enea.it

\begin{abstract}
To improve the collaboration between scientific communities working within geographically distributed laboratories, it is increasingly necessary to take into account the complexity of data streaming process and the difficulties with integrating heterogeneous instruments of different groups of researchers (Mongelli et al., 2017). This paper shows the 'ENEA staging storage sharing' (E3S) architecture developed within the COBRA project (http://cobra.enea.it/english) which promotes the technology transfer to small and medium-sized companies for the conservation of cultural heritage. This architecture was setup for the shaking tables at the Sustainable Innovation Technologies (SITEC) ENEA Casaccia R.C. Laboratory and it was used during experimental tests on two masonry walls made up of stone and tuff blocks that represent the poor Italian masonry of historical buildings, to verify the behaviour of innovative techniques of anti-seismic reinforcement. E3S supports the whole experimental process, from photogrammetric reconstruction to FEM calibration, reducing time needed to obtain experimental results by means real time data streaming functions.
\end{abstract}

Keywords: sharing experiments; near real time results; high performance computing; seismic protection; numerical models; FEM calibration.

Reference to this paper should be made as follows: Mongelli, M., Bellagamba, I., Iannone, F. and Bracco, G. (2018) 'From 2D digital imaging to finite element analysis using the ENEAGRID high performance computing infrastructure for the preservation of historical masonry structures', Int. J. Masonry Research and Innovation, Vol. 3, No. 3, pp.324-347. 
Biographical notes: Marialuisa Mongelli graduated in Chemical Engineering at the University of Rome 'La Sapienza' (1991). She obtained the PhD in Metallurgy at the 'Politecnico' of Turin (1996). Since 2004, she is a researcher at the ENEA Casaccia in Rome. Her research activities are mainly directed to the field of seismic protection of civil and historical structures to develop anti-seismic devices and retrofitting systems, within Italian and European research programs. She is involved in the development of numerical models, from photogrammetric 3D reconstruction to FE analysis and in NDT controls to assess the structural integrity of structures. She is also involved in many experimental campaigns within the Italian and European research programs regarding in situ and laboratory NDTs to seismic protection.

Irene Bellagamba graduated in Civil Engineer at the University of Rome 'Roma Tre' in 2015. After her first experience in an engineering company as a Design Engineer of hydraulic works, she obtained a fellowship 'Orio Carlini' at the GARR, working in the development of web interfaces for the real time sharing of experimental seismic tests, conducted at ENEA Casaccia R.C. in Rome. She is also involved in other activities in the field of cultural heritage protection, valorisation and preservation by the development of numerical models, from photogrammetric $3 \mathrm{D}$ reconstruction to $\mathrm{FE}$ analysis.

Francesco Iannone graduated in Physics at Naples University in 1987. He worked in a geophysical company, using ground penetration radar and seismic survey, as responsible of data acquisition processing. In 1993, he was engaged by ENEA as a researcher in renewable energies. Since 1997, he worked in ENEA Nuclear Fusion Department as a specialist in data acquisition systems of the main Italian experiment in magnetic confinement nuclear fusion (Frascati Tokamak Upgrade). He has developed instrumentation and controls in hard real-time operating systems and geographical distributed data handling in physics experiments. Since 2016, he is in charge of the ENEA HPC laboratory as an expert in HPC facilities for nuclear fusion modelling.

Giovanni Bracco graduated in Experimental Nuclear Physics at the University of Pavia in 1976. After some experience in IBM Italia as a System Engineer, he obtained a EURATOM Fellowship at the Fontenay-aux-Roses CEA Center near Paris, working in nuclear fusion domain. In 1981, he got a permanent position in the ENEA Nuclear Fusion Department working on plasma diagnostics and in developing tools for integrated data analysis and codes for plasma energy transport modelling. In 2003, he moved to the ICT ENEA Department, working in the implementation of ENEA HPC infrastructure, including the participation in GRID (ICT infrastructure) related projects, as datagrid and EGEE. Since 2010, he is in charge of the ENEA HPC Laboratory, developing and managing CRESCO clusters and ENEAGRID computing infrastructure.

This paper is a revised and expanded version of a paper entitled 'Seismic experimental data sharing and FE calibration on scaled mock-ups of historic masonry structures through the ENEA CRESCO infrastructure' presented at PROHITECH 17, 3rd International Conference on Protection of Historical Constructions, 12-15 July 2017. 


\section{Introduction}

ENEA staging storage sharing (E3S) architecture is based on the OwnCloud framework (https://owncloud.org; https://wiki.geant.org/display/OCM/Open+Cloud+ Mesh) and allows to synchronise the local staging areas of the experimental data acquisition system (DAS) that are closed in the lab local area network (LAN), with the ENEA storage area, AFS and GPFS, for world-wide sharing (Ponti et al., 2014).

The architecture was applied for the real time sharing of experimental data produced in terms of displacement during shaking tables test thanks to a motion capture 3D system installed at the Sustainable Innovation Technologies (SITEC) laboratory (Beraldin et al., 2004; De Canio et al., 2016). Safety and integrity of data sharing, storage and post processing are assured both locally and through remote access tools on a geographic network by the ENEAGRID infrastructure. The architecture allows not only remote real-time data signal and video streaming, but also sharing of the experimental data files at the end of each single step. Moreover, by ENEA Computational Research Centre for Complex Systems (CRESCO) facilities, users can access to high performance graphics tools for remote implementation of $\mathrm{FE}$ models and 3D photogrammetric models (Mongelli et al., 2016). This paper shows the E3S architecture on the case study of two masonry walls, to verify their dynamic behaviour under the action of increasing seismic inputs induced by shaking tables. Before testing the masonry walls, a 3D photogrammetric reconstruction of the two walls was produced by structure from motion (SfM) technique through the ENEAGRID infrastructure, which allows to use 'computer graphics' tools, exploiting the computational resources offered by the HPC CRESCO infrastructure and to archive images and photogrammetric reconstructions results in the AFS and GPFS ENEA storage areas. The SfM technique produces a 3D scaled numerical model as 'points cloud' and it allows to obtain correct geometrical data of the two specimens in terms of shape, size and space position. Consequently, the FE models based on real geometry were defined and FE modal analysis was carried on in order to understand the dynamic behaviour of the structures, to evaluate stress and strain distribution and to estimate the modal parameters, which are a measure of the structural damage evolution.

\section{Case study}

The experimental sessions were performed on two masonry walls made up of stone and tuff blocks (Figure 1). The walls are made up of typical materials that represent the poor masonry characterising the historical buildings of the Centre of Italy. At the beginning, during the first experimental campaign, the specimens were tested without any type of anti-seismic reinforcement, in order to study their dynamic response in terms of magnitude and to evaluate the out of plane actions until their collapse (Al Shawa et al., 2012). After their collapse, the two specimens were repaired and a new high-strength 'composite' reinforcing fibres (Fraternali et al., 2015; Fabbrocino et al., 2015), produced by Kerakoll $\mathrm{SpA}$, was tested, in order to verify their seismic capacity. The experimental campaign was also performed within a Italy-USA project, titled Composites with Inorganic Matrix for Sustainable Strengthening of Architectural Heritage for cooperation and technology transfer. During the first test session, five Italian seismic inputs (Bagnoli, Mirandola, Amatrice, Nocera and L'Aquila) were executed at increasing intensity from 
$25 \%$ to $125 \%$ of real accelerograms. All tests were shared in real time both with project partners (University of Roma Tre and University of Miami) and with researchers and experts working in the field of seismic protection in a remote configuration, by structural dynamic, numerical simulation, qualification tests and vibration control (DySCo) virtual laboratory via Adobe Connect (De Canio et al., 2013) and by E3S architecture via RBNB DataTurbine (DT) technology (http://dataturbine.org; http://dataturbine. org/documentation/setting-up-a-sink/real-time-dataviewer-rdv/) for near real-time data managing and visualisation (Fountain et al., 2012).

Figure 1 Front and lateral views of the two specimens

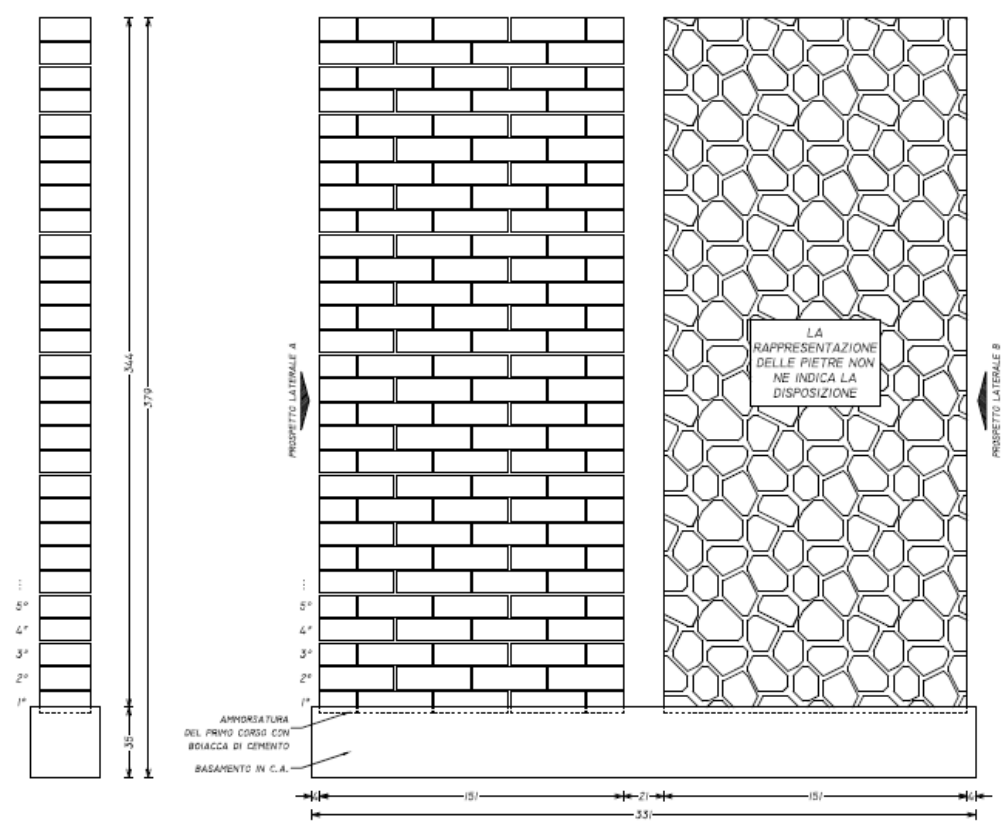

\section{Shaking table and 3DVision DAS}

The experimental tests on the two real-scale walls in Figure 2 were performed by a 6-degree-of-freedom very large shaking table $(4 \mathrm{~m} \times 4 \mathrm{~m})$ and the displacement data were acquired by a 3D motion capture system named 3DVision, which uses a constellation of four video and ten new NIR high resolution digital MX cameras of last generation which are mounting Vicon VEGAS-4 CMOS sensors with a full frame resolution of five megapixels up to $350 \mathrm{fps}$; the sampling frequency is set to $200 \mathrm{~Hz}$. The system provides an easy calibration of the measured volume, a greater uniformity of acquisition and a faster image processing, minimising the network load during the near real-time data streaming. Retro-reflecting wireless markers are fixed on the tested structure in the most critical areas which came from a preliminary FE modal analysis. The system is able to track the 3D trajectories of hundreds of markers placed at the measurement points of the structure during the seismic tests with easy and fast test setup and high accuracy. The trajectories were saved into a C3D file created at the end of each step of the experimental 
test. The NIRs were arranged around the two specimens so as to cover the entire measurement volume and to optimise the calibration process of the cameras themselves.

Figure 2 The real-scale mock-ups on the shaking table (see online version for colours)

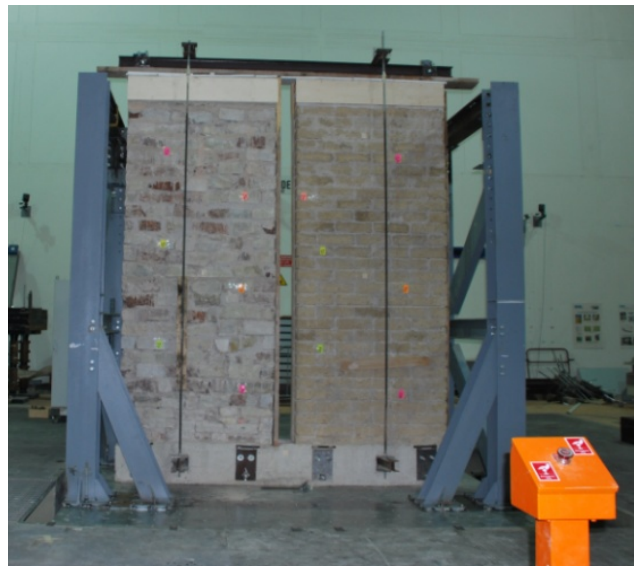

\section{Real time experimental tests sharing by DySCo virtual lab}

As the shaking table tests test went on, the experimental results were shared in real time thanks to the possibility to synchronise visible and NIR cameras in a networking configuration, the DySCo virtual lab (http://www.afs.enea.it/project/Dysco/) developed for seismic applications (Roselli et al., 2010).

Figure 3 DySCo virtual room based on Adobe Connect (see online version for colours)

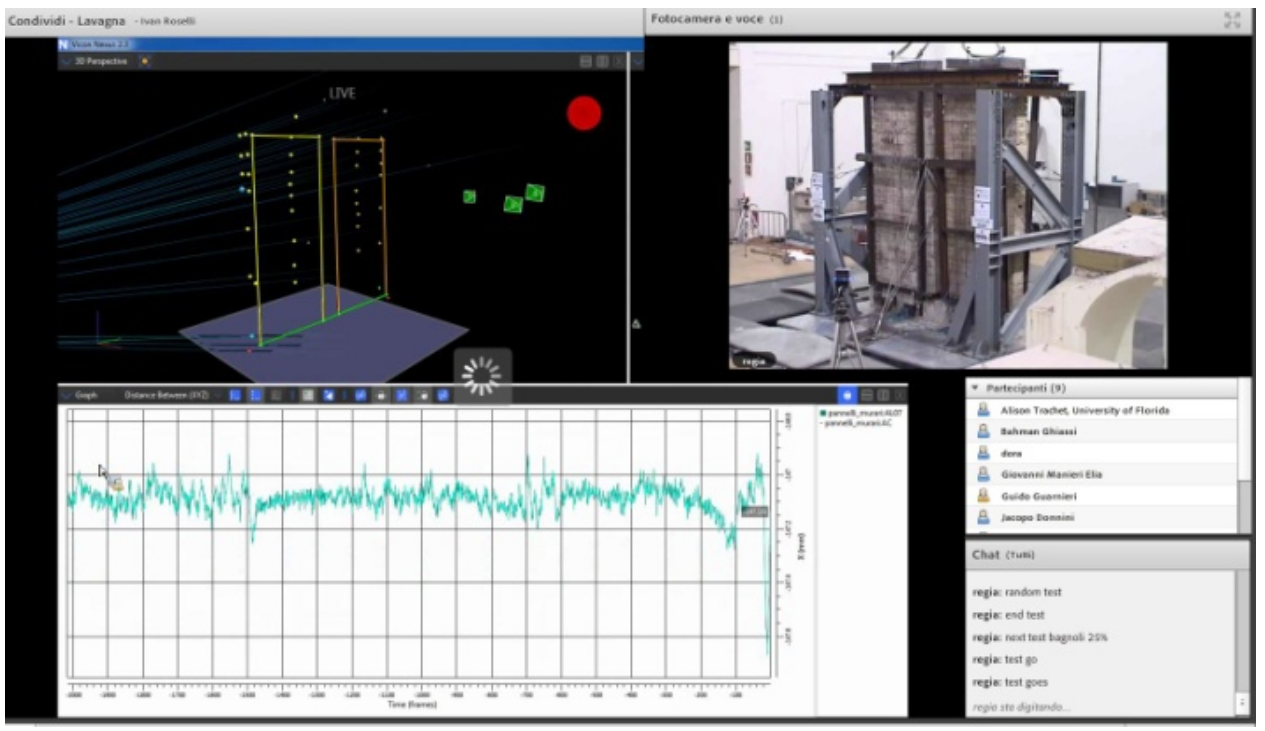


A general-purpose friendly web interface allows real time data sharing and gives an integrated access to the stored experimental results, experiments video streaming, storage areas and numerical simulation.

Remote users, with secure authentication, can access the experimental sessions through a virtual room based on Adobe Connect (https://connect.portici.enea.it/tavibr) which allows the streaming of control console, data, audio and webcams and to interact step by step with the operators and the researchers in the lab (Figure 3).

Remote users have also the possibility to access the graphical tools, installed on ENEAGRID infrastructure, by an intuitive and user-friendly interface, named fast access to remote objects (FARO2). This graphical interface gives the possibility to run series or parallel heavy jobs of scientific codes for finite element structural analysis, exploiting the resources offered by the HPC CRESCO infrastructure.

\section{$5 \quad$ E3S architecture}

Within the COBRA project, which promotes technology transfer to small and medium-sized companies, aiming at the dissemination of technologies and tools for the conservation of cultural heritage, the E3S architecture based on the OwnCloud framework was developed and tested on the two masonry walls experimentally tested by shaking tables. It allows to synchronise the local staging areas of the laboratory DAS, that is connected to the lab local area network (LAN), with the ENEA storage area, AFS and GPFS, for world-wide sharing (Figure 4).

Figure 4 E3S general schema (see online version for colours)

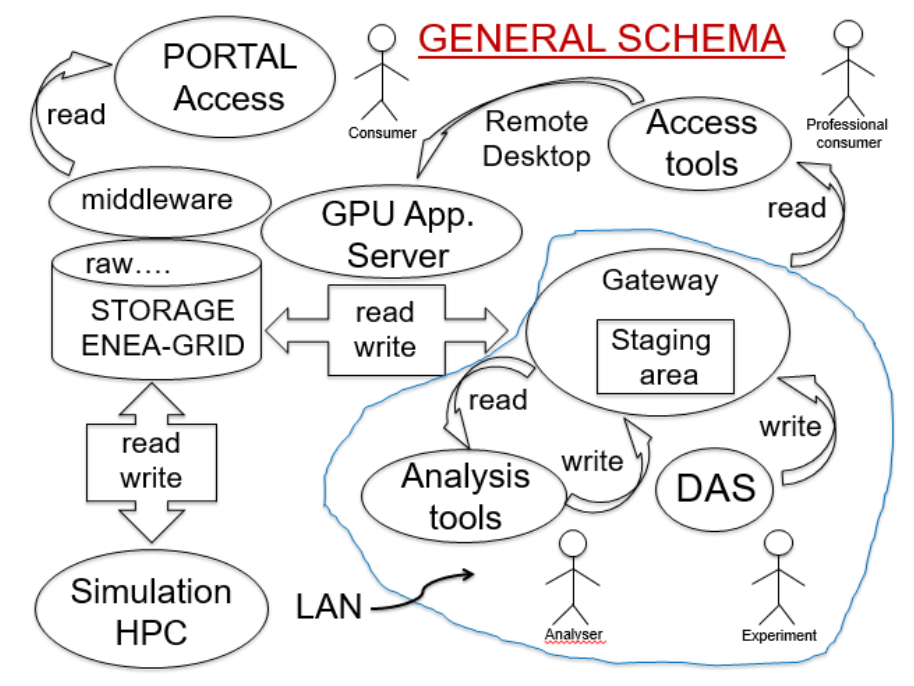

Improving the collaboration between scientific communities, working within laboratories geographically distributed in the world, has to take into account the complexity of the data streaming process as well as the difficulties of integrating heterogeneous instruments and technologies. This is often linked to the ability to transfer via web experimental data and results, ensuring a high degree of data quality/integrity and protection. For these 
reasons, E3S has been designed assuming data integrity and security, scalability and reliability as fundamental requirements.

Data integrity is guaranteed by a file synchronisation process between staging and storage areas, while the data protection and security are provided by a single-signed on authentication and authorisation system, based on the Kerberos 5 protocol.

Figure 5 (a) OwnCloud GUI (b) OwnCloud client (see online version for colours)

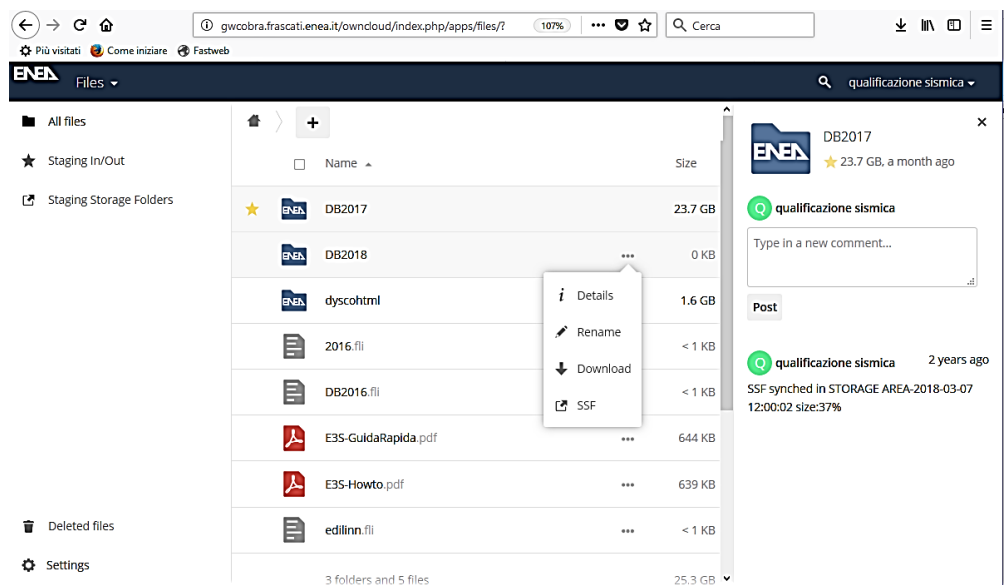

(a)

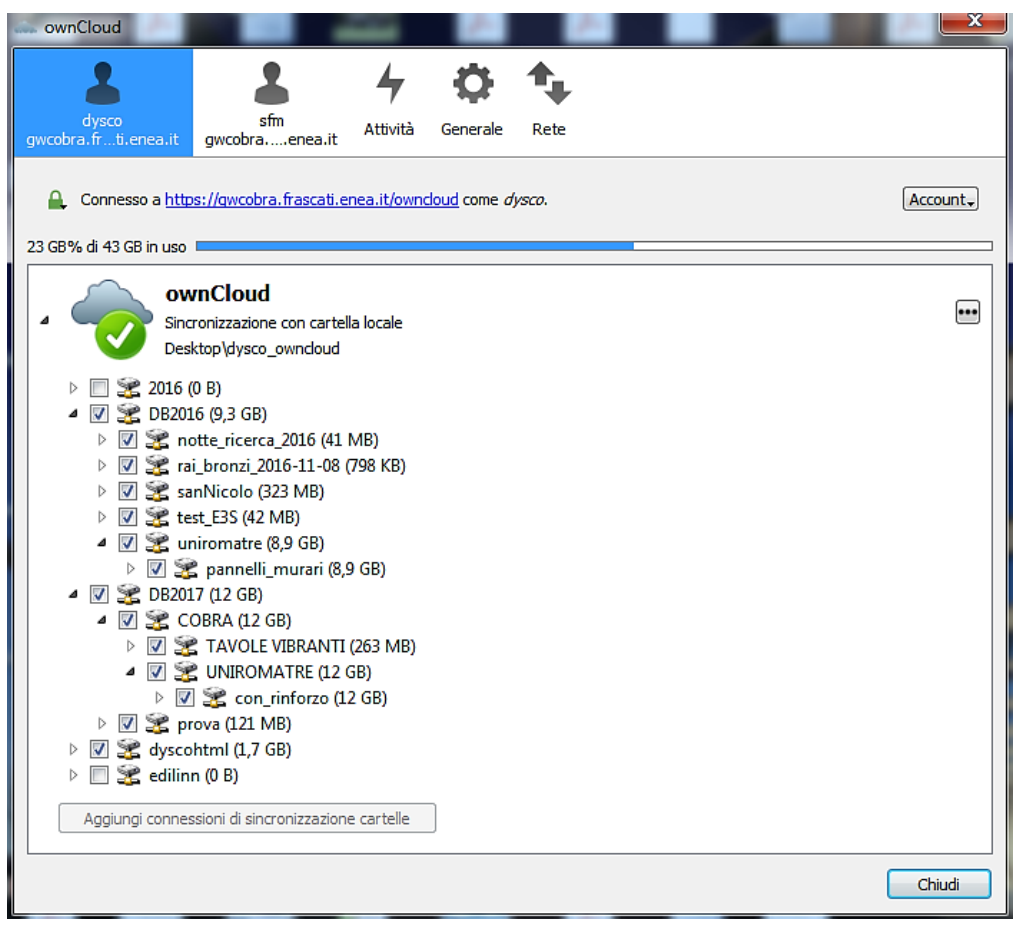

(b) 
As soon as the experimental data are stored locally in the DAS laboratory, they are synchronised on a C3D file that is copied on the ENEAGRID infrastructure. The OwnCloud framework allows the user in charge of the test to store the experimental data in the local staging area through the OwnCloud web interface, only accessible from the lab LAN or, alternatively, through the OwnCloud client, which can be installed on any device (Figure 5).

Once the staging area is synchronised with the AFS storage area, experimental data are shared with remote users who can access data from the same web interface.

\section{Streaming and data managing by DySCO Logbook and DT application}

A web application based on LAMP platform (Linux Apache MySQL PHP), named 'DySCo Logbook', was developed to collect metadata and trigger near real-time streaming of data and video of the experiment. This application uses a specific MySQL database named 'dyscodw' and it is made up of two section: the 'insert/modify' section (Figure 6) is only available within the laboratory LAN by the user in charge of the test, who can extract metadata from the C3D file, save them into 'dyscodw' DB and launch the java script for signals and videos streaming by the DT application.

Figure 6 Insert/modify section of DySCo Logbook (see online version for colours)

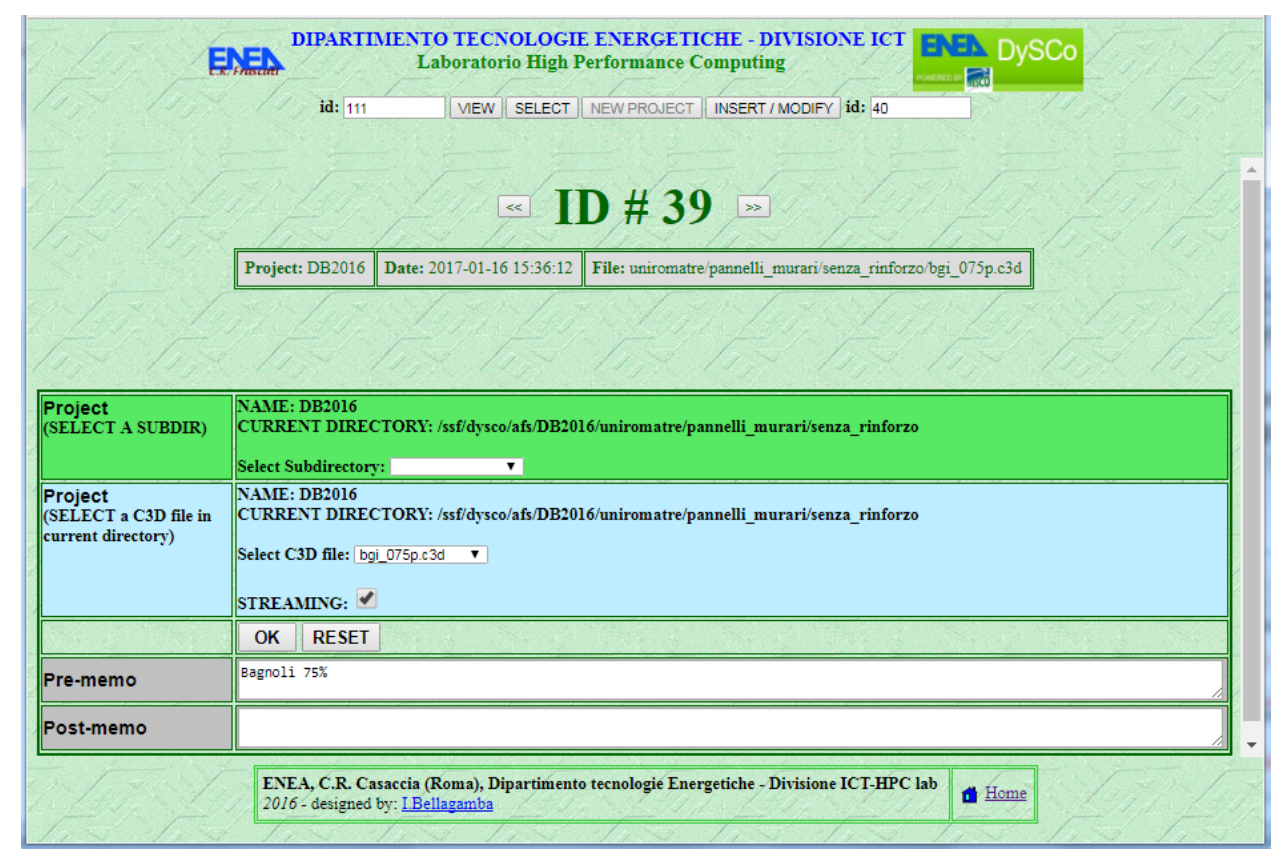

The 'view' section, accessible from WAN, allows remote users to visualise at any moment any information related to each acquisition step:

- $\quad$ number of markers (measurement points)

- number of acquisition frame 
- number of analogue channel

- frame rate.

Moreover, this section allows to visualise for each record, the position in a 3D space of all markers positioned on the structure during the tests, their number and the label associated to each one. In this way, remote users have the possibility to select a specific marker to visualise in complete autonomy the $X, Y, Z$ components of its trajectory, as shown in Figure 7.

Figure 7 View section of DySCo Logbook (left) and $X, Y, Z$ components of marker trajectories (right) (see online version for colours)

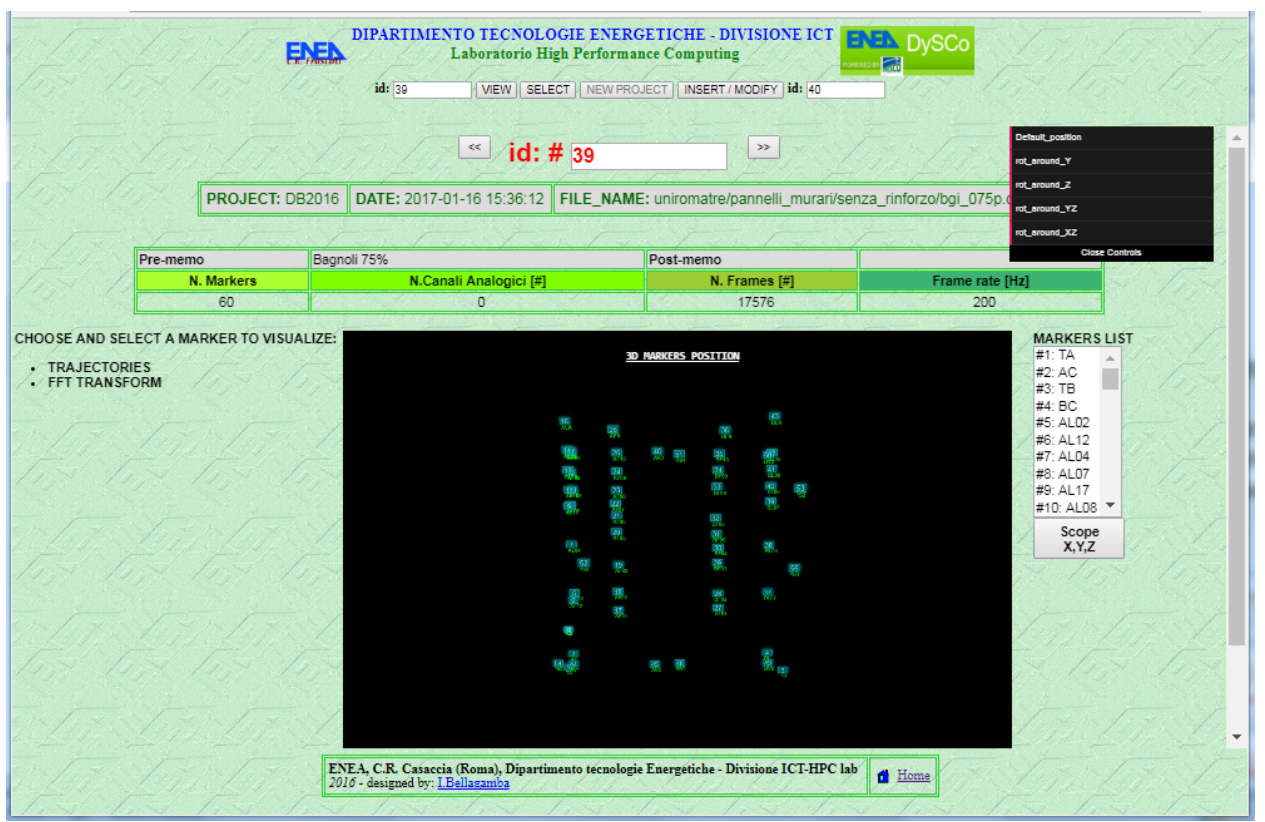

The DT system is used to stream and share the trajectories of all markers installed on the structure during shaking table tests. In fact, it allows to manage and stream real time experimental data. In addition to working with live data, DT can stream archived data as if they were live, reutilising common data viewers and infrastructure for post-test data analysis and review.

The RDV DT interface is shown in Figure 9.

The shaking table tests are made of a sequence of test steps, gradually increasing the seismic input intensity, until reaching a certain level of damage of the specimen.

Finite element analyses (FEAs) are very useful to understand the dynamic behaviour of the tested structure, mapping its stress and strain distribution and estimating its modal parameters, which are crucial to evaluate the structural damage. But this process is very time-consuming and the level of damage reached by the specimen after each test step is evaluated only by visual inspection. The DT system can reduce time consuming by means of data managing and real time streaming functions, providing reliable data transport for a wide range of sensors. The experimental data acquired by the 3DVision system and the video from the test are streamed and shared with remote project partners 
via DT and the damage level of the structures, reached at the end of each acquisition step, is used as the real seismic input for the FEA. Results are then compared with the experimental data for calibrating the material properties and the boundary conditions of the FE model.

Figure 8 Streaming process by DT (see online version for colours)

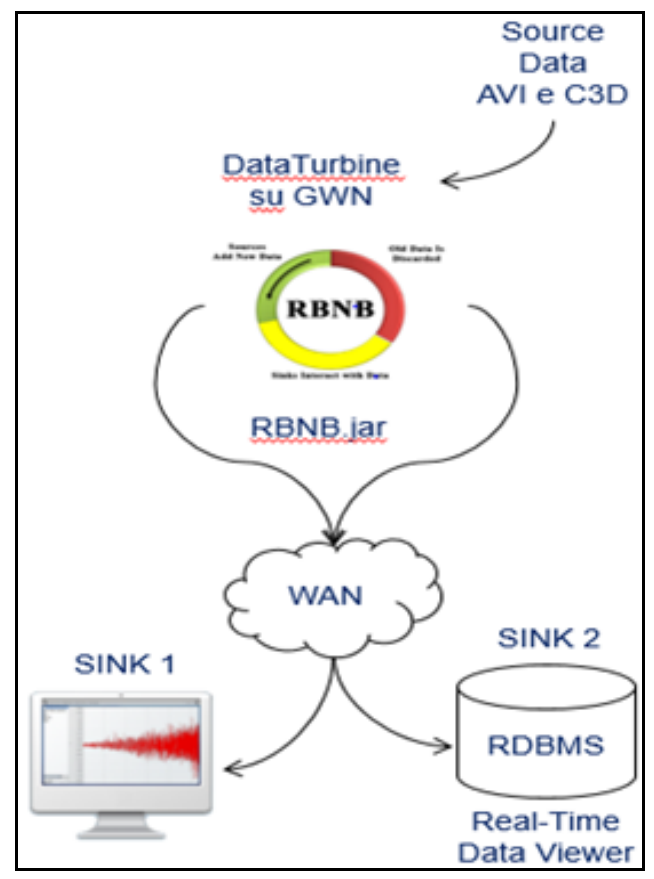

Figure 9 RDV DT interface (see online version for colours)

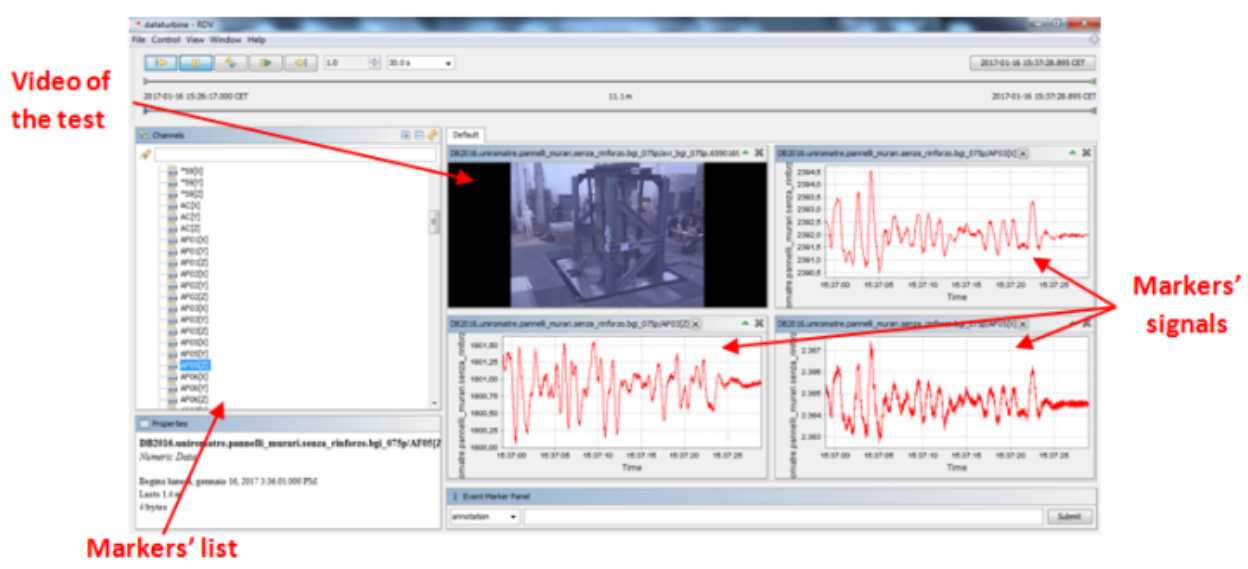




\section{3D photogrammetric reconstructions of the masonry walls}

Before testing the masonry walls by shaking table tests, a 3D photogrammetric reconstruction was produced (Arias et al., 2005; McCarthy, 2014), by the $S f M$ method (Roncella et al., 2011). This technique, based on photogrammetric principles, is used to create three-dimensional models of the two masonry walls, under the form of 'points cloud' and/or 'polygonal mesh', in order to obtain their correct geometrical data in terms of shape, size and spatial position. The SfM has many advantages (Westobya et al., 2012): it is a fast, not invasive and not destructive technique which executes the moving scan of the tested structures in a 'contactless' way, with the aim to create, in a semi-automatic way, the finite elements models and to execute the FE analysis, taking into account their real geometry.

\subsection{Photogrammetry: general principles}

From the acquisition of two-dimensional digital images, the photogrammetric technique allows to obtain the correct measures of a detected object in terms of shape, size and 3D space position (Patmios and Lazaridou, 2000).

This technique can be distinguished into two field based on the acquisition method:

- Aerial photogrammetric technology: for the 3D reconstruction of the territorial morphology.

- Close range photogrammetric technology: it is used when the acquisition distance is less than 300 metres.

The close range technique is particularly used for the reconstruction of architectonical elements, small objects or structures with the purpose to carry out structural investigations and FE models of the structures. The photogrammetric reconstruction process is made up of three main steps:

1 camera location and orientation

2 2D digital images acquisition

3 3D reconstruction of the object.

Three fundamental parameters must be related to define the photogrammetric reconstruction process: 2D image/images coordinates, 3D object coordinates and orientation parameters.

The photogrammetric theory is based on some analytical relations used to determinate an univocal correspondence between the points located in the 'object space' (images space) and the points of the real 3D space. The 'projection' law rules the relation between the $2 \mathrm{D}$ and the $3 \mathrm{D}$ space, by means of the parametric matrix $A$, through equation $u=A U$, which in matrix form become:

$$
\left[\begin{array}{c}
u_{i} \\
v_{i} \\
t
\end{array}\right]=\left[\begin{array}{llll}
a_{1} & a_{2} & a_{3} & a_{4} \\
a_{5} & a_{6} & a_{7} & a_{8} \\
a_{9} & a_{10} & a_{11} & a_{12}
\end{array}\right] \cdot\left[\begin{array}{c}
U_{i} \\
V_{i} \\
W_{i} \\
T
\end{array}\right]
$$


where $u$ is a vector that represents the position of a point in the 'object space', $U$ is the vector that represents the position of the point in the real space and $A$ is the 'transform matrix'.

Referring to the coordinate system above mentioned, the relation become $u=k B X$, that in matrix form is as follows:

$$
\left[\begin{array}{c}
x_{i} \\
y_{i} \\
1
\end{array}\right]=\left[\begin{array}{llll}
b_{1} & b_{2} & b_{3} & b_{4} \\
b_{5} & b_{6} & b_{7} & b_{8} \\
b_{9} & b_{10} & b_{11} & b_{12}
\end{array}\right] \cdot\left[\begin{array}{c}
X_{i} \\
Y_{i} \\
Z_{i} \\
1
\end{array}\right]
$$

where $k$ is a 'scale factor'.

These equations allows to reconstruct the position of a point in a three-dimensional space, furthermore, the projection centre, the real point and the corresponding point on the image, lie on the same line.

A single image cannot univocally identify any point in a 3D space because every possible point which lie on the line that links the projection centre $O$ to the 'image point' $p$ may have the projection on the same point $p$. For this reason, a second image is needed, with the aim to obtain some information about the depth (see Figure 10).

Figure 10 Point triangulation through a couple of images (see online version for colours)

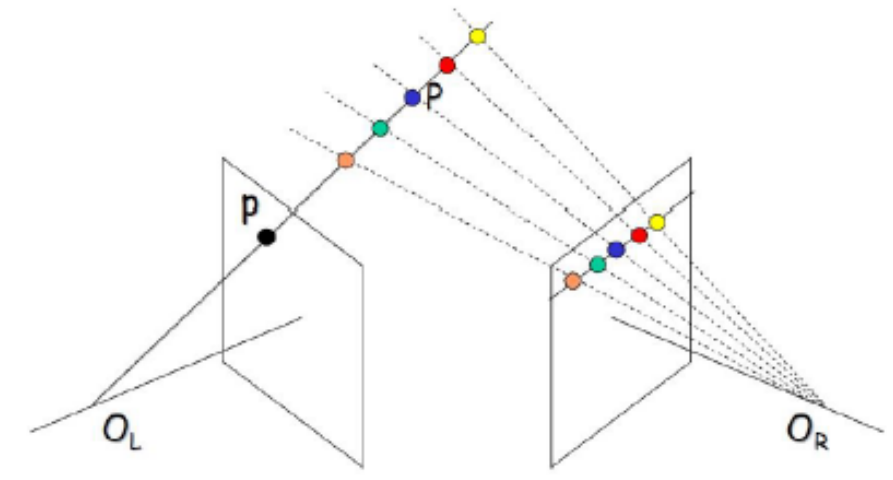

This process is called triangulation: to obtain the position of an object in a 3D space two images are needed, catching the object from two different positions. The same point, detected on each image is called 'homologue point'.

\subsection{The 'collinearity equations'}

In order to obtain the $X, Y, Z$ coordinates of a point in a 3D space, the following nine parameters are needed:

- Internal frame orientation (see Figure 11): defined by the principal distance $c$ and the coordinates $(x, y, z)$ of the principal point $\left(P P^{\prime}\right)$;

- External camera orientation, defined by six values, three spatial coordinates and three rotation angles. 
Figure 11 Central perspective

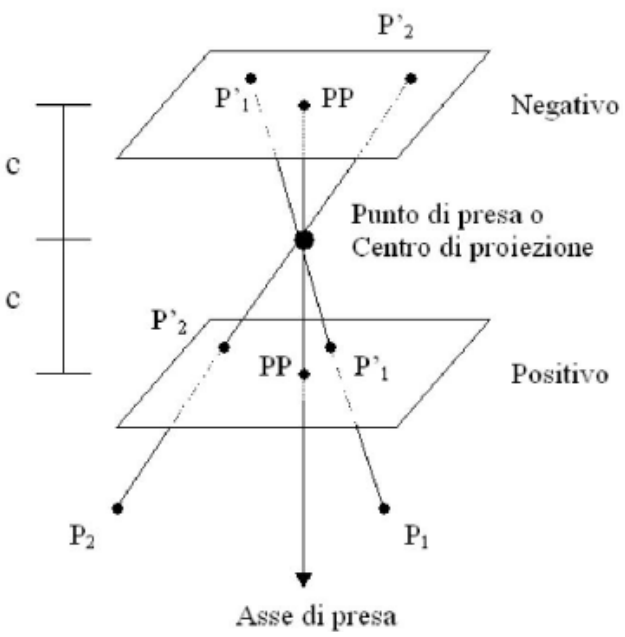

The internal frame orientations can be obtained from the camera characteristics, while the other parameters must be obtained by topographic methods (GPS and inertial system) or by indirect methods, using the so called 'support points'.

According to the theory of the central projection, the point in the real 3D space, the frame centre and the point projected on the 'image plane' are all aligned along the same line.

The 'collinearity equations' describe the projection transformation between the 'camera sensor space' and the real 'object space':

$$
\left[\begin{array}{c}
X \\
Y \\
Z
\end{array}\right]=\lambda_{i j} R_{j}\left[\begin{array}{c}
x_{i j}-x_{0 j} \\
y_{i j}-y_{0 j} \\
z_{i j}-z_{0 j}
\end{array}\right]+\left[\begin{array}{c}
X_{0} \\
Y_{0} \\
Z_{0}
\end{array}\right]_{j}
$$

where (see Figure 12):

- $\quad X_{i}, Y_{i}$ and $Z_{i}$ are the space coordinates of the point $P_{i}$

- $\quad X_{0 j}, Y_{0 j}$ and $Z_{0 j}$ are the coordinates of the camera shot centre

- $\quad x_{i j}$ and $y_{i j}$ are the 'image' coordinates measured from the photo shot centre $P^{\prime}{ }_{i j}$

- $\quad x_{0 j}$ and $y_{0 j}$ are the 'image' coordinates of the principal point $O_{i j}^{\prime}$

- $\quad c_{j}$ is the focal distance

- $\quad R_{j}$ is the matrix rotation between the 'image' space and the 'object' space

- $\quad \lambda_{i j}$ is a scale factor

- $\quad i=1, \ldots, n$ number of points of the image

- $j=1, \ldots, m$ number of images. 
The internal orientation is defined by the parameters $x_{0 j}, y_{0 j}$ and $c_{j}$ while the external orientation is defined by the coordinates $X_{0 j}, Y_{0 j}$ and $Z_{0 j}$ and the three rotation angles belonging to the rotation matrix $R_{j}$.

These equations allows to obtain the three-dimensional model of the object, detecting camera orientation and camera position within a 3D space, consequently the scale factor can be deleted and equations become two:

$$
\begin{gathered}
x_{i j}=-c_{j} f_{i j}^{x}+x_{0 j}=-c_{j} \frac{r_{11 j}\left(X_{i}-X_{0 j}\right)+r_{21 j}\left(Y_{i}-Y_{0 j}\right)+r_{31 j}\left(Z_{i}-Z_{0 j}\right)}{r_{13 j}\left(X_{i}-X_{0 j}\right)+r_{23 j}\left(Y_{i}-Y_{0 j}\right)+r_{33 j}\left(Z_{i}-Z_{0 j}\right)} \\
y_{i j}=-c_{j} f_{i j}^{y}+y_{0 j}=-c_{j} \frac{r_{12 j}\left(X_{i}-X_{0 j}\right)+r_{22 j}\left(Y_{i}-Y_{0 j}\right)+r_{32 j}\left(Z_{i}-Z_{0 j}\right)}{r_{13 j}\left(X_{i}-X_{0 j}\right)+r_{23 j}\left(Y_{i}-Y_{0 j}\right)+r_{33 j}\left(Z_{i}-Z_{0 j}\right)}
\end{gathered}
$$

where $r_{11 j}, \ldots, r_{33 j}$ are the elements of the rotation matrix $R_{j}$.

Figure 12 Relation between real point and projection point

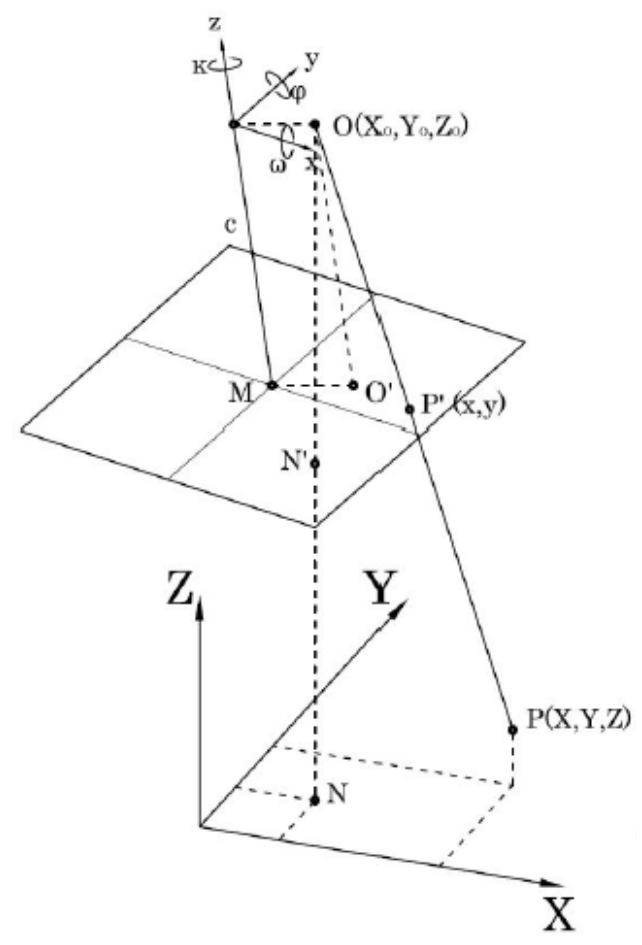

Because of the deformation and the distortions (radial and tangential) introduced by the camera optical components, the mathematical model is affected by systematic errors. For this reason, the $\Delta x_{i j}$ and $\Delta y_{i j}$ coordinate corrections may be introduced, taking into account, the geometry of the camera sensors:

$$
\begin{aligned}
& x_{i j}=-c_{j} f_{i j}^{x}+x_{0 j}+\Delta x_{i j} \\
& y_{i j}=-c_{j} f_{i j}^{y}+y_{0 j}+\Delta y_{i j}
\end{aligned}
$$


These final equations can be solved by the use of sophisticated algorithms to calculate the unknown parameters, represented by the internal and the external orientation.

\subsection{The SfM technique}

The SfM technique is based on the theoretical principles of optics, the descriptive geometry fundamentals and in particular on the inverse perspective theory. This technique can be applied to many fields of cultural heritage protection and conservation because it allows to obtain in a fast, contactless and easy way, a 3D model of the structure under the form of 'points cloud', starting from the acquisition of two-dimensional images, detecting the correct geometrical data in terms of shape, size and space position.

One of the principal obstacles for the use of this technique is due to the large demands of hardware and software resources for image processing, data analysis and data storage. The possibility to access the computational resources offered by the ENEAGRID infrastructure, through the so called FARO2 graphical interface, allows to use 'computer graphics' tools, offered by the HPC CRESCO facilities. Furthermore, the E3S architecture offers a scaled cloud framework, which allows to archive a large number of digital images and the heavy results of the photogrammetric reconstructions in the AFS and the GPFS ENEA storage areas, thanks to the possibility to access the OwnCloud web interface.

Consequently, the photogrammetric reconstruction of the two masonry walls are made-up by the use of the computer vision software, named Agisoft PhotoScan, installed on the CRESCO infrastructure.

The SfM technique is different from the photogrammetric method, because the scene reconstruction as well as the camera position and orientation are solved in an automatic way by the software, using complex algorithms.

From a set of $m$ images, representing $n$ real points, the problem consists of estimating the $m$ projections matrix $P_{j}$ and the $n$ vectors $X_{i}$, by the given $n m$ correspondences $x_{i j}$ and the theoretical fundamentals are the above mentioned 'collinearity equations'. They represent a mathematical model which associates to the coordinates of the points belonging to a bi-dimensional sensor, the three-dimensional coordinates of the points belonging to a real $3 \mathrm{D}$ object.

Figure 13 Projection of a point belonging to different images (see online version for colours)

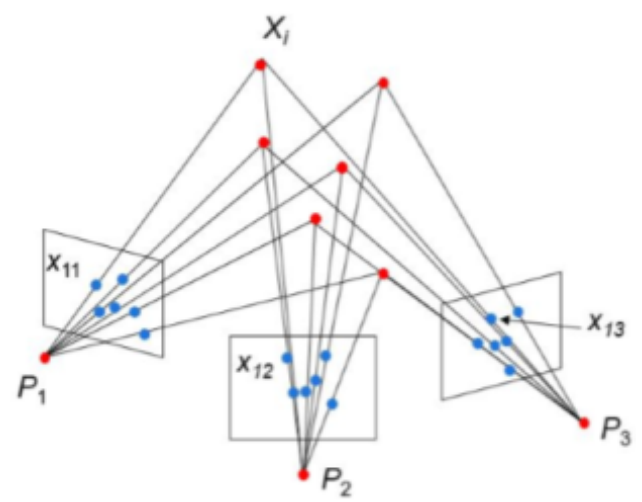


Each reconstruction step of the SfM technique provides the use of specific algorithms that are light-independent, in fact they are able to recognise the 'principal features' or 'remarkable points' of an object, starting from the acquired digital images, even if they are characterised by different light conditions and then a database is created.

Subsequently, on the base of the previous detected features, an image matching process is performed, which consists in grouping all the images that have some points in common. These acquired information are managed by a 'bundle adjustment' software, which detects the internal and external orientations as well as the 'features positions'.

Figure 14 Matching features step (see online version for colours)

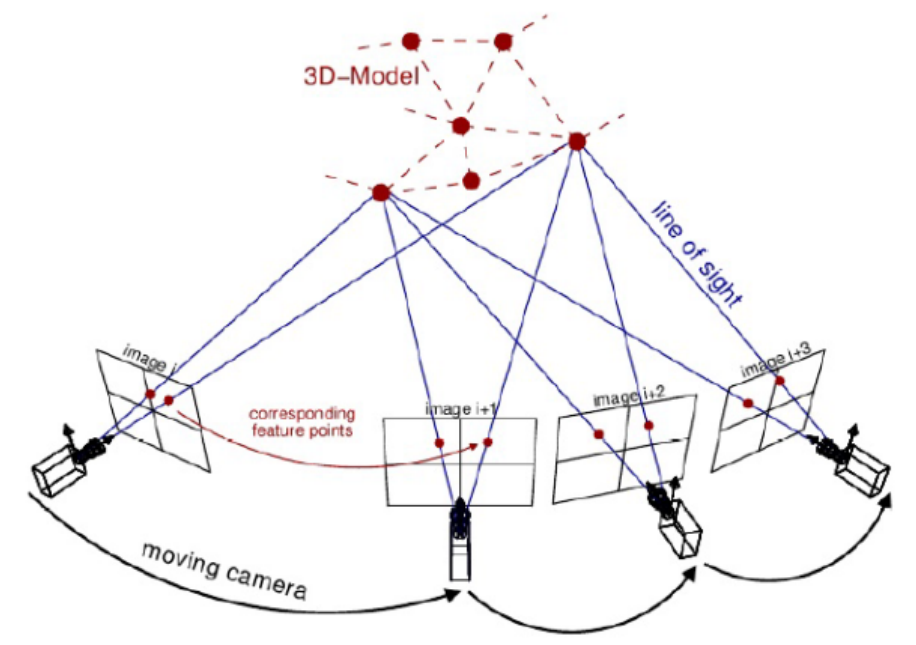

The 'bundle adjustment' is a camera calibration process, based on the 'collinearity equations', that allows to calculate the correction parameters of radial and tangential distortions, minimising the 're-projection' error, which represents the distance between the projected point and the measured point.

The final result of this step is a 'sparse points cloud', consisting of the features detected previously, i.e., the points characterised by three spatial coordinates and a chromatic information obtained from the images.

All the parameters previously calculated are used by a 'dense image matching algorithm' that extracts a 'dense points cloud', thanks to a depth comparison between images. A vector and a triad of chromatic values (RGB: red, green, blue) are associated to each point belonging to the dense cloud.

Some photo-modelling software can also reconstruct a polygonal model, made of triangular elements, faces and vertices (meshes), as PhotoScan does. Then, thanks to the information obtained from the photos shots orientation, a 'texture mapping' step allows to create a final polygonal texturised model of the structure.

\subsection{The masonry walls reconstruction by SfM}

Thanks to the use of the computational resources offered by CRESCO, Agisoft PhotoScan can manage a large number of images, with the possibility to create 
high-quality polygonal models of the two specimens, characterised by a multi-view reconstruction.

To obtain a good photogrammetric 3D model of the tested structures by SfM, 207 images have been acquired and post-processed by PhotoScan.

The main PhotoScan 'work session' is the chunk, a container of all the images acquired for the reconstruction of the models. In some cases, when a large number of images (more than 400) are needed, two or more chunks must be created, with the aim to separate the elaborations. The subdivision of the reconstruction process into two or more chunks allows to obtain a greater control of the 3D model quality and to reduce time-consuming. All the chunks that contain each single part of the mock-up are then aligned and merged, reconstructing the whole model of the structure.

For the reconstruction of the two walls, only one chunk is needed, because of the limited number of the acquired images.

The image post-processing procedure is based on 'computer vision' algorithms, it is easy and semiautomatic and it can be resumed as Figure 15.

Figure 15 PhotoScan workflow

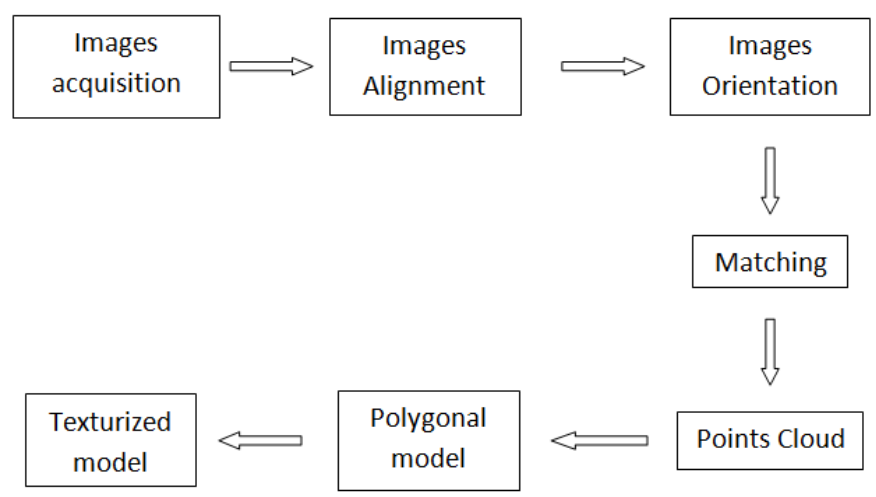

The first step of the elaboration process performed by PhotoScan is the alignment of the loaded images loaded images: by means the SIFT algorithm and the multi-stereo matching process, the position and the orientation of the camera shots are detected and a 'sparse cloud' of the two specimens is created.

Subsequently, a 'dense image matching' algorithm allows to extract the 'dense cloud' model, thanks to a depth comparison between all the images. The results of this step are shown in Figure 16.

PhotoScan also allows to reconstruct the polygonal model, made of faces and vertices, which can be obtained from the point belonging to the dense points cloud. Then, a texture process is performed, to obtain the final 'texturised model' of the specimens.

PhotoScan permits to choose between two different methods to create the texture: the mosaic method, based on the projection of the image with the best resolution on each portion of the model; the average method, which takes into account the average value of the single pixel characterising all the images. The final polygonal model of the two masonry walls, obtained from the SfM reconstruction, is shown in Figure 17. Figure 17(a) shows the polygonal model without the texture, while in Figure 17(b) is shown the final 'texturised model'. 
Figure 16 Dense cloud model (see online version for colours)

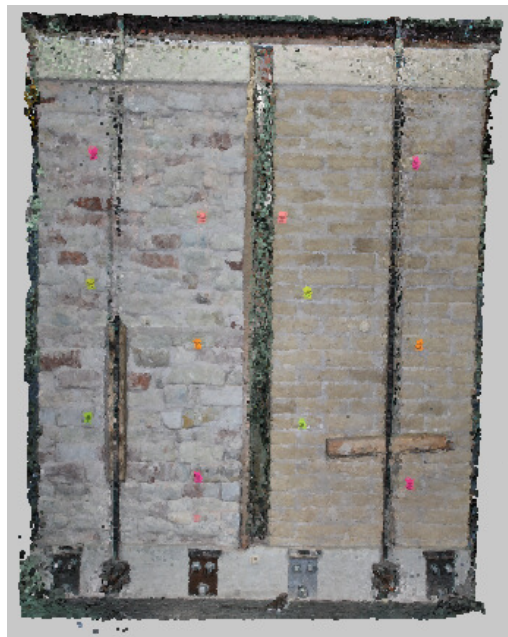

Figure 17 3D polygonal model of the walls (see online version for colours)

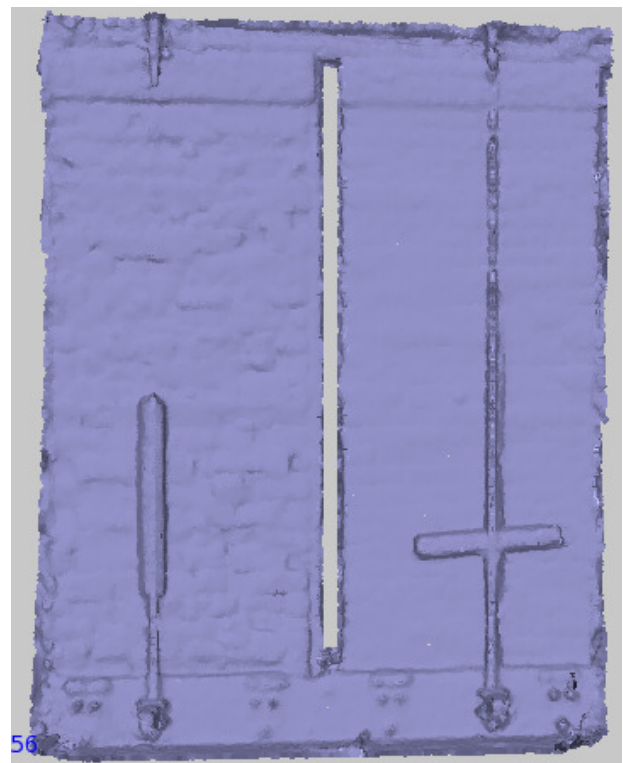

(a)

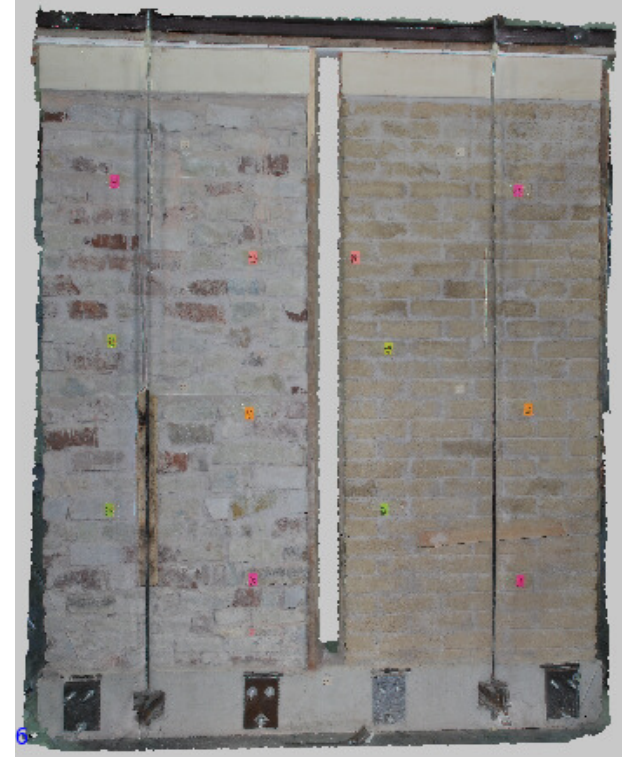

(b)

Table 1 Geometrical dimensions

\begin{tabular}{lcc}
\hline & Tuff wall & Stone wall \\
\hline Height [m] & 3.45 & 3.45 \\
Thickness [m] & 0.26 & 0.26 \\
Width [m] & 1.56 & 1.52 \\
\hline
\end{tabular}


With the aim to detect the real dimensions of the two specimens, for the execution of the FE analysis, a scaled polygonal model is created. PhotoScan provides a fast and automatic way to scale the models, starting from the acquisition and the assignment of a single reference measure of the real structures.

Table 1 summarises the real dimensions of the two specimens, obtained by the SfM reconstruction.

\section{From the SfM model to FEM}

The photogrammetric model of the two walls is used to obtain their real geometry in terms of shape and size, by using an alternative technique of geometry relief, which is contactless and easy to use. The SfM method can be also used to execute the geometrical relief of structures with difficult access and/or complex geometry.

The 3D model of the specimens has been imported in a finite element code for the execution of the modal analysis, to identify the resonance frequencies and the modal shapes of the structures (Fabbrocino, 2016). Then, the results obtained from the FE analysis have been compared with the experimental data.

The E3S 'GPU application server' (GAS) is an important functional component which provides an integrated graphical environment for the execution of many applications, included FE analysis, on multiple hardware platforms, based on remotely accessible graphic processing units (GPU). Thanks to the possibility to access the GAS, it has been possible to run heavy jobs for FE analysis, using the computational resources offered by CRESCO HPC muli-core clusters. In fact, the FE model and the modal analysis of the two masonry walls were executed by Abaqus, a software installed on ENEAGRID IT infrastructure and accessible by the graphical interface FARO2 (see Figure 18).

Figure 18 Remote access to FE software (see online version for colours)

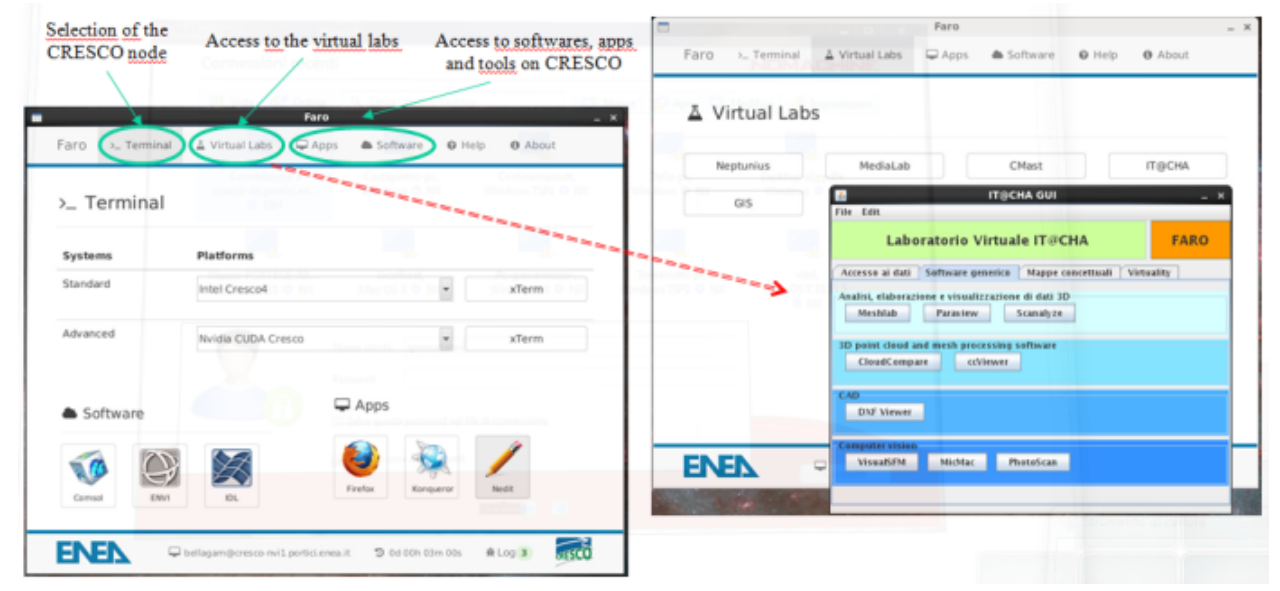

The material properties assigned to the FE models of the structures, evaluated by literature for the stone blocks and by compression tests on the tuff blocks are illustrated in Table 2. 
Table 2 Material properties of the specimens

\begin{tabular}{lccc}
\hline & Elastic module E $[\mathrm{MPa}]$ & Density $\rho\left[\mathrm{Kg} / \mathrm{m}^{3}\right]$ & Poisson coeff. $v$ \\
\hline Tuff wall & 1,575 & 1,600 & 0.18 \\
Stones wall & 2,400 & 2,400 & 0.15 \\
Upper curb concrete & 31,000 & 1,700 & 0.2 \\
Lower curb concrete & 31,000 & 2,500 & 0.2 \\
\hline
\end{tabular}

Two distributed masses of $600 \mathrm{Kg}$ weight were put on the top of each model. The Abaqus FE models are made of 540 exa8 solid elements.

The FE model of the tuff wall is shown in Figure 19, the model of the stone wall has the same characteristics, in terms of number and type of solid elements.

Figure 19 FE model of the tuff wall (see online version for colours)

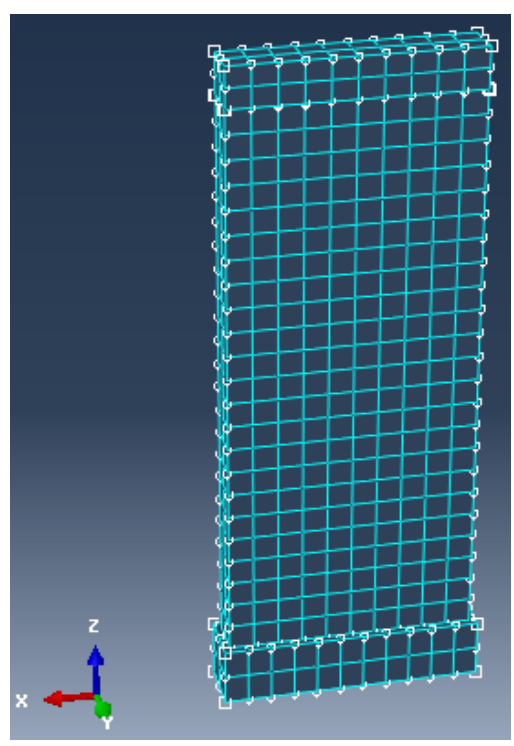

With the aim to simulate a vertical flexional mechanism of the walls a horizontal 'cylindrical hinge' constraint has been created.

The vertical flexion may involve:

- One or more levels of the wall: it depends on the connections between different horizontal elements.

- The whole width of the wall or the only external vestment: it depends on the structural characteristics of the wall.

- Different parts of the wall: it depends on the presence of openings, discontinuities and/or localised actions.

In order to simulate the out-of-plane mechanism, representing the mechanism of vertical blending, the constraints assigned (Figure 20) to the models are: 
- A joint at the base of the structure (BC-1) to simulate the strong connection between the walls and the foundations or the underlying slab.

- A carriage on the top of the wall, which allows the vertical displacement and the rotation around a single axis ( $X$ axis), as shown in Figure 20 (BC-2).

Figure 20 Constraints assignment (see online version for colours)
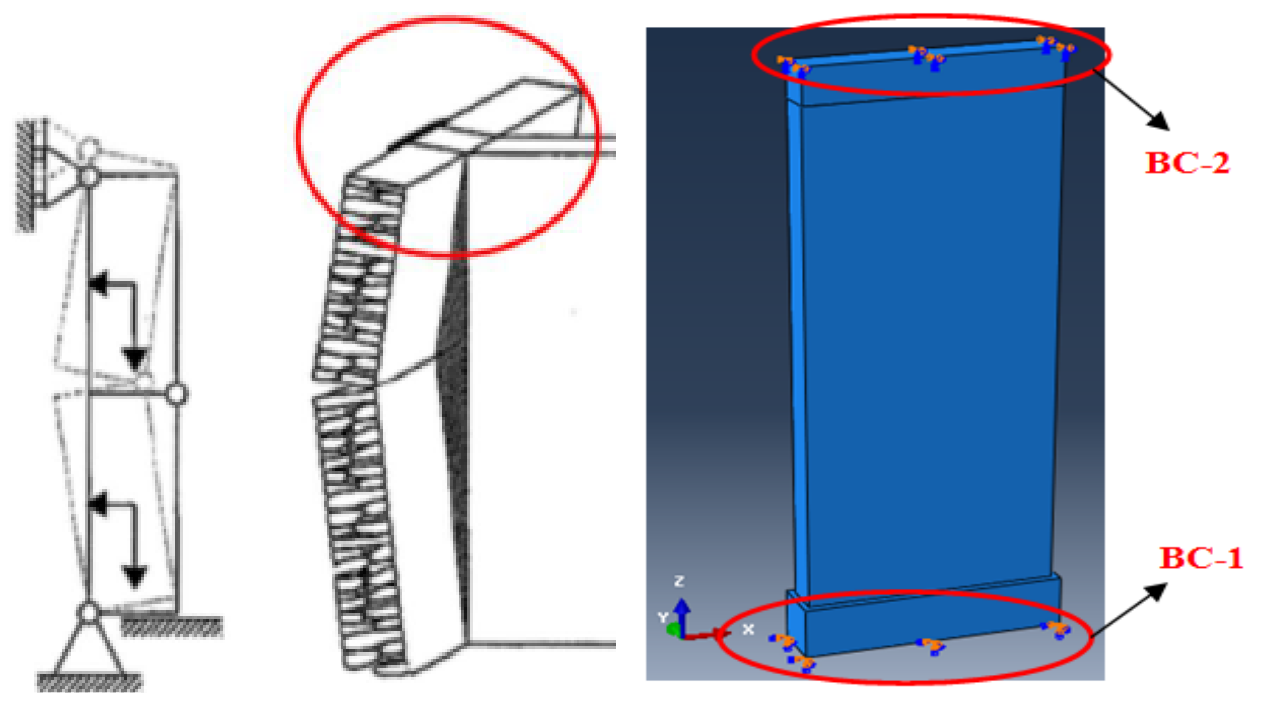

Figure 21 (a) 1, (b) 2 and (c) 3 modal shapes (see online version for colours)

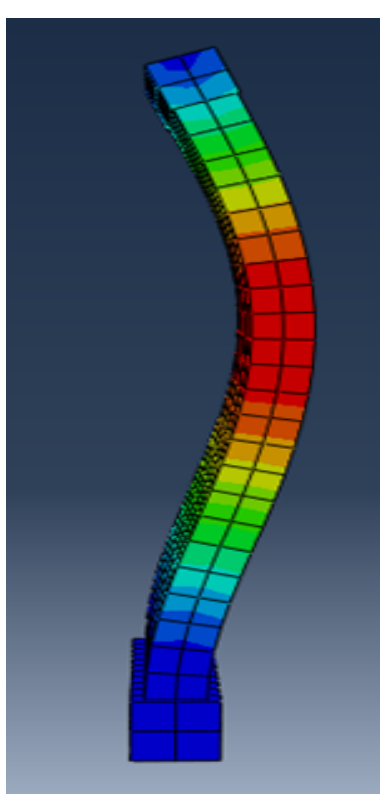

(a)

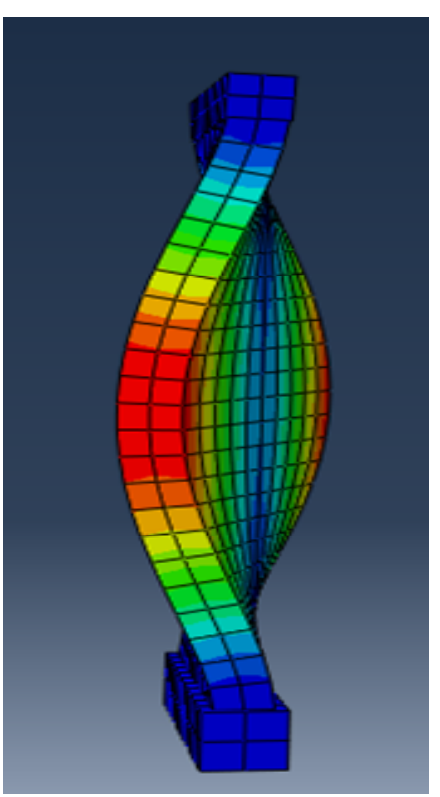

(b)

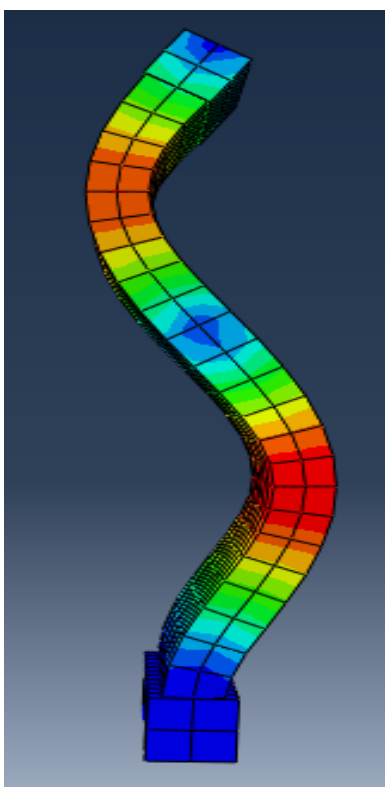

(c) 
The results of the finite element modal analysis for the two masonry walls, in terms of resonance frequencies are resumed in Table 3. They have been compared with the frequencies obtained from the displacement signals acquired by the 3DVision system and streamed in real time by the DT application.

Table 3 Resonance frequencies

\begin{tabular}{ccccccc}
\hline & \multicolumn{2}{c}{ FEA results } & & \multicolumn{2}{c}{ Experimental results } \\
\cline { 2 - 3 } \cline { 5 - 6 } & Tuff wall & Stone wall & & Tuff wall & Stone wall \\
\hline Frequency [HZ] & 9.65 & 7.47 & & 9.67 & 7.82 \\
\hline
\end{tabular}

Note: 1st modal shape.

The first three modal shapes of the two walls are shown in Figure 21.

\section{Conclusions}

Numerical methods from 3D photogrammetric reconstruction to FE analysis are proposed as a preventive method which allows to detect, monitor and track the damage evolution of some structural problems detected, in a network configuration of sharing experimental tests by shaking table. The staging, storage and sharing (E3S) system with the DySCO Logbook and DT for data streaming and data managing, developed at the ENEA CRESCO infrastructure to improve the capabilities of the DySCO virtual lab within the COBRA project, aims to introduce a new approach on the side of the sharing and management of experimental tests and data results. It takes advantage of all the reliability and performances of a distributed file system like AFS or GPFS by an easy to use interface. It is fully integrated in the existing data acquisition procedures of the SITEC laboratory performed by shaking tables, in order to improve the research cooperation and dissemination in the field of seismic protection but it is applicable to other instruments and laboratories

\section{Acknowledgements}

The computing resources and the related technical support used for this work have been provided by CRESCO/ENEAGRID High Performance Computing infrastructure and its staff. CRESCO/ENEAGRID High Performance Computing infrastructure is funded by ENEA, the Italian National Agency for New Technologies, Energy and Sustainable Economic Development and by Italian and European research programs, see http://www. cresco.enea.it/english for information. A special thanks to all colleagues involved in the management and operation of the infrastructure ENEAGRID/CRESCO, software (system and/or applications), hardware, network and general support. 


\section{References}

Al Shawa, O., de Felice, G., Mauro, A. and Sorrentino, L. (2012) 'Out-of-plane seismic behaviour of rocking masonry walls’, Earthq. Eng. Struct. D, Vol. 41, No. 5, pp.949-968.

Arias, P., Herraez, J., Lorenzo, H. and Ordonez, C. (2005) 'Control of structural problems in cultural heritage monuments using close-range photogrammetry and computer methods', Computers \& Structures, August, Vol. 83, Nos. 21-22, pp.1754-1766.

Beraldin, J.A., Latouche, C., El-Hakim, S.F. and Filiatrault, A. (2004) 'Applications of photo-grammetric and computer vision techniques in shake table testing', Proceedings of the 13th World Conference on Earthquake Engineering (13WCEE), Vancouver, BC, Canada.

CO.B.RA. Project [online] http://cobra.enea.it/english (accessed 21 July 2015).

De Canio, G., de Felice, G., De Santis, S., Giocoli, A., Mongelli, M., Paolacci, F. and Roselli, I. (2016) 'Passive 3D motion optical data in shaking table tests of a SRG-reinforced masonry wall', Earthquake and Structures, Vol. 10, No. 1, pp.53-71.

De Canio, G., Mongelli, M. and Roselli, I. (2013) '3D motion capture application to seismic tests at ENEA Casaccia research center. 3DVision system and DySCo virtual lab', Wit. Trans. Built. Env., Vol. 134, pp.803-814, ISSN 1743-3509

Fabbrocino, F. (2016) 'Estimation of the natural periods of existing masonry towers through empirical procedure', International Journal of Sustainable Materials and Structural Systems, August, ISSN: 2043-8621, DOI: 10.1504/IJSMSS.2016.078711.

Fabbrocino, F., Farina, I., Berardi, V.P., Ferreira, A.J.M. and Fraternali, F. (2015) 'On the thrust surface of unreinforced and FRP-/FRCM-reinforced masonry domes', Composites. Part B, Engineering, Vol. 83, pp.297-305, ISSN: 1359-8368, DOI: 10.1016/j.compositesb.2015. 08.061

Fountain, T., Tilak, S., Shin, P. and Nekrasov, M. (2012) 'The open source DataTurbine initiative: empowering the scientific community with streaming data middleware', Bulletin of the Ecological Society of America, Emerging Technologies, July, Vol. 93, No. 3, pp.242-252, DOI:10.1890/0012-9623-93.3.242.

Fraternali, F., Carpentieri, G., Modano, M., Fabbrocino, F. and Skelton, R.E. (2015) 'A tensegrity approach to the optimal reinforcement of masonry domes and vaults through fiber-reinforced composite materials', Composite Structures, Vol. 134, pp.247-254, ISSN: 0263-8223, DOI: 10.1016/j.compstruct.2015.08.087.

McCarthy, J. (2014) 'Multi-image photogrammetry as a practical tool for cultural heritage survey and community engagement', Journal of Archeological Science, March, Vol. 43, pp.175-185, ISSN: 03054403, DOI:10.1016/j.jas.2014.01.010.

Mongelli, M., Bellagamba, I., De Canio, G., Giovanetti, G., Iannone, F., Pierattini, S., Roselli, I., Migliori, S., Quintiliani, A., Ambrosino, F., Bracco, G., Funel, A., Guarnieri, G. and Ponti, G. (2017) 'Seismic experimental data sharing and FE calibration on scaled mock-ups of historic masonry structures through the ENEA CRESCO infrastructure', Proceedings of the 3rd International Conference on Protection of Historical Constructions, Lisbon, Portugal.

Mongelli, M., Roselli, I., De Canio, G. and Ambrosino, F. (2016) 'Quasi real-time FEM calibration by 3D displacement measurements of large shaking table tests using HPC resources', Advances in Engineering Software, 19 July, DOI: 10.1016/j.advengsoft.2016.07.005 30.

Patmios, E. and Lazaridou, M. (2000) 'Education on photogrammetry remote sensing and GIS. experiences, criticism, revisions', in The International Archives of the Photogrammetry, Remote Sensing and Spatial Information Sciences, Vol. 33, Part B6, pp.231-233, Amsterdam, The Netherlands.

Ponti, G. et al. (2014) 'The role of medium size facilities in the HPC ecosystem: the case of the new CRESCO4 cluster integrated in the ENEAGRID infrastructure', Proceedings of the 2014 International Conference on High Performance Computing and Simulation, HPCS 2014, Art. No. 6903807, pp.1030-1033. 
Roncella, R., Re, C. and Forlan, G. (2011) 'Performance evaluation of a structure and motion strategy in architecture and cultural heritage', International Archives of the Photogrammetry, Remote Sensing and Spatial Information Sciences, 2011 ISPRS Trento 2011 Workshop, Vol. 38-5/W16, Trento, Italy, 2-4 March.

Roselli, I., Beone, F., Colucci, A., De Canio, G., Mencuccini, G. and Mongelli, M. (2010) 'The DYSCO virtual lab for seismic and vibration tests at the ENEA', Proceedings of the 10th European Conference on Earthquake Engineering (10ECEE), Ohrid, Macedonia.

Westobya, M.J., Brasingtonb, J., Glassera, N.F., Hambreya, M.J. and Reynoldsc, J.M. (2012) 'Structure-from-Motion photogrammetry: a low-cost, effective tool for geoscience applications', Geomorphology, 15 December, Vol. 179, pp.300-314, DOI:10.1016/j.geomorph.2012.08.021. 